\title{
Der Krieg der Richter findet nicht statt
}

\section{Maximilian Steinbeis}

2010-08-26T11:51:09

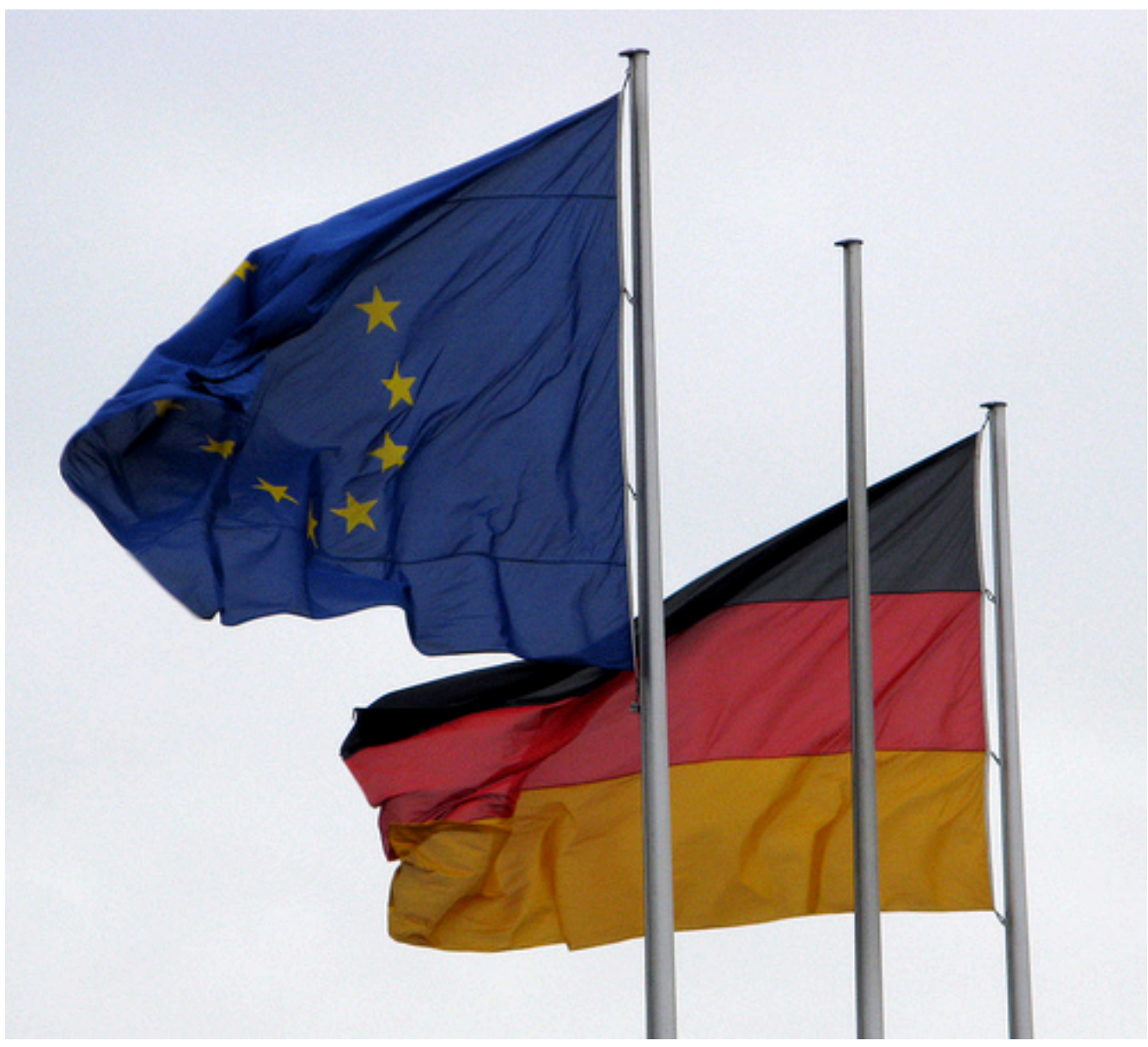

Die Meuterei der nationalen Verfassungshüter gegen die Europäisierung des Rechts und ihre damit einhergehende eigene Relativierung ist vorbei. Die Rebellen aus Karlsruhe kehren reumütig zurück unter die blaue Fahne mit dem goldenen Sternenkreis. Frieden kehrt ein in Europa.

Verzeihung, aber da darf man schon mal pathetisch werden bei so einer Nachricht. Ich kann gar nicht sagen, wie mich die heute veröffentlichte Honeywell-Entscheidung des Bundesverfassungsgerichts freut und erleichtert.

\section{Mangold, Lissabon, Kücükdeveci}

Zur Vorgeschichte: Der EuGH hatte 2005 das berüchtigte Mangold-Urteil gefällt und darin die Behauptung aufgestellt, Altersdiskriminierung sei in der EU schon immer verboten, als "allgemeiner Grundsatz des Gemeinschaftsrechts", und nicht erst durch eine entsprechende Richtlinie (deren Umsetzungsfrist zu dem Zeitpunkt noch nicht abgelaufen war). Dies werteten manche als Versuch des EuGH, die inm zugewiesenen richterlichen Kompetenzen zu durchbrechen und sich zum 
Gesetzgeber aufzuschwingen - was so von den Mitgliedsstaaten nie intendiert war und daher die im Maastricht-Urteil definierten Grenzen des durch Art. 23 GG Erlaubten sprenge ("ultra vires").

Diese Meinung bekam mächtig Auftrieb durch das Lissabon-Urteil des Zweiten Senats, das dem EuGH ziemlich unverblümt den Kampf ansagte und die Ultra-ViresGrundsätze des Maastricht-Urteils noch ausbaute.

Der EuGH, auch nicht faul, legte daraufhin mit dem Kücükdeveci-Urteil noch einen drauf.

Im jetzt entschiedenen Fall geht es um eine Verfassungsbeschwerde des Automobilzulieferers Honeywell, der 2003 mit einem Mitarbeiter einen befristeten Arbeitsvertrag abgeschlossen hatte, der sich aufgrund des Diskriminierungsverbots wegen Alters als unbefristet herausstellte. Dazu gab es zwar 2003 noch überhaupt kein Gesetz, aber der 2005 im Mangold-Urteil erfundene "allgemeine Grundsatz", dass Altersdiskriminierung verboten ist, war ja dem EuGH zufolge irgendwie schon immer da und daher auch in diesem Fall unmittelbar anwendbar. Dies focht Honeywell in Karlsruhe an - eine Konstellation, die unmittelbar zum Showdown zwischen EuGH und Bundesverfassungsgericht zu führen schien.

\section{Erst eine Art Staatsstreich wäre ultra vires}

Jetzt aber rückt der Zweite Senat ein paar Dinge gerade:

Wenn jeder Mitgliedstaat ohne weiteres für sich in Anspruch nähme, durch eigene Gerichte über die Gültigkeit von Rechtsakten der Union zu entscheiden, könnte der Anwendungsvorrang praktisch unterlaufen werden, und die einheitliche Anwendung des Unionsrechts wäre gefährdet.

Ultra-Vires-Kontrolle muss schon sein, aber nur "zurückhaltend und europarechtsfreundlich". Das bedeutet zweierlei:

- Erstens muss das Bundesverfassungsgericht, bevor es ein Ultra-Vires-Urteil fällt, in jedem Fall per Vorlage an den EuGH diesem Gelegenheit geben, auf die verfassungsrechtlichen Bedenken einzugehen. Das heißt: Karlsruhe legt in Luxemburg vor. So, wie zum Beispiel das Arbeitsgericht Cottbus in Karlsruhe vorlegt. No less.

- Zweitens reicht nicht jeder Kompetenzverstoß, um Karlsruhe auf den Plan rufen zu können. Es muss sich im Grunde schon um eine Art Staatsstreich handeln.

Bloße Rechtsfortbildung durch den EuGH sei auf keinen Fall berührt; die sei inm sogar explizit erlaubt, stellt der Senat ausdrücklich klar (das las sich in Lissabon auch noch anders). Aufgabe und Eigenart des EuGH seien zu respektieren, ebenso ein großzügigerweise eingeräumter Anspruch auf "Fehlertoleranz".

Allerdings, das betont der Senat dann schon auch, wenn die Rechtsfortbildung in die Richtung einer Kompetenz-Kompetenz gehe, dann höre der Spaß auf. 
Fazit: Was Solange II für Solange I war, was das Bananenmarkt- für das MaastrichtUrteil war, das ist Honeywell für Lissabon. Wieder einmal hat der Zweite Senat gebellt, aber gottlob nicht gebissen.

\section{Den Schaden zahlt Schäuble}

Und was wird aus Mangold? Von einem Staatsstreich ist das Urteil erkennbar weit entfernt - eine Feststellung, für die der Senat dann doch wieder erstaunlich detaillierte Ausführungen für nötig hält. Aber von ultra vires könne jedenfalls keine Rede sein.

Dem Kläger, der auf das Teilzeit- und Befristungsgesetz vertraut hatte und von dem "allgemeinen Grundsatz des Gemeinschaftsrechts", der das Gesetz aushebelte, nichts wissen konnte, weist der Senat auf andere Weise die Richtung, in der er sein Recht suchen soll: Er solle die Bundesrepublik auf Schadensersatz verklagen. Europarechtlich sei es

möglich, zur Sicherung des verfassungsrechtlichen Vertrauensschutzes in Konstellationen der rückwirkenden Nichtanwendbarkeit eines Gesetzes infolge einer Entscheidung des Gerichtshofs innerstaatlich eine Entschädigung dafür zu gewähren, dass ein Betroffener auf die gesetzliche Regelung vertraut und in diesem Vertrauen Dispositionen getroffen hat. Auch das unionsrechtliche Haftungsrecht weist dem Mitgliedstaat die Verantwortung für ein unionsrechtswidriges Gesetz zu und entlastet insoweit den Bürger. Es kann offen bleiben, ob ein entsprechender Anspruch bereits im bestehenden Staatshaftungssystem angelegt ist.

Bemerkenswert ist auch, was der Senat zu der Frage schreibt, ob es das Recht auf einen gesetzlichen Richter verletzt, wenn ein Gericht in Luxemburg vorlegen müsste, es aber nicht tut. Eine Kammer des Ersten Senats hatte erst vor wenigen Monaten entschieden, dass die Instanzrichter ihre Pflicht, vorzulegen, am Maßstab der Rechtsprechung des EuGH dazu prüfen müssen - und Karlsruhe einschreiten kann, wenn sie das nicht tun.

Das sieht der Zweite Senat anders: Erst eine willkürliche, offensichtlich unhaltbare Abweichung von den Vorgaben des EuGH sei als Verstoß gegen das Recht auf den gesetzlichen Richter zu werten. Denn sonst würde Karlsruhe zu einer Art "oberstes Vorlagekontrollgericht", und das sei nicht sein Job.

\section{Respekt für Di Fabio}

Sechs der acht Richter stehen hinter dieser Urteilsbegründung. Nur Herbert Landau zeigt mit seinem Minderheitsvotum, dass er Peter Gauweiler nicht nur in der Wahl der Barttracht nahe steht. Das Votum ist vor allem deshalb lesenswert, weil es schön auflistet, in welchen Punkten das Lissabon-Urteil jetzt alles überholt ist.

Ein weiterer Richter wollte die Begründung nicht mittragen. Meine Vermutung: Broß. Das hieße, dass Di Fabio mit der Mehrheit gestimmt hat. Meinen Respekt. 
Der Senatsvorsitzende Voßkuhle hat jedenfalls sein Versprechen, die LissabonBombe unter Kontrolle zu bringen, eingelöst und sich seinen Präsidentenjob so im Nachhinein auf das Zufriedenstellendste verdient. 